\title{
ESFR SMART PROJECT CONCEPTUAL DESIGN OF IN-VESSEL CORE CATCHER
}

\author{
Joel Guidez ${ }^{1}$, Antoine Gerschenfeld ${ }^{1}$, Janos Bodi ${ }^{2}$, Konstantin Mikityuk ${ }^{2}$, Francisco \\ Alvarez-Velarde ${ }^{3}$, Pablo Romojaro ${ }^{3}$, U. Diaz-Chiron ${ }^{3}$ \\ ${ }^{1}$ Commissariat à l'énergie atomique et aux énergies alternatives (CEA) \\ CEN SACLAY 91190 Gif sur Yvette France \\ ${ }^{2}$ Paul Scherrer Institut (PSI) \\ Forschungsstrasse 111, 5232 Villigen, Switzerland \\ ${ }^{3}$ Centro de Investigaciones Energéticas, Medioambientales y Tecnológicas (CIEMAT) \\ Av. Complutense, 40, 28040 Madrid, Spain
}

joel.guidez@cea.fr, antoine.gerschenfeld@cea.fr, janos.bodi@psi.ch,konstantin.mikityuk@psi.ch, francisco.alvarez@ciemat.es, pablo.romojaro@ciemat.es, unai.diaz-chiron@ciemat.es

\begin{abstract}
Even before Fukushima accident occurred, the safety authorities have required that new power plant designs must take into account beyond design-basis accidents including possible core meltdown. Among the mitigation strategies, the corium retention must be ensured, so a core catcher is implemented in the design of the Generation IV Sodium-cooled Fast Reactor. An internal core catcher within the vessel (in-vessel retention) is the option chosen for the European Sodium-cooled Fast Reactor investigated in the H2020 ESFR-SMART project.

The new core investigated in ESFR SMART with lower void effect has a better behavior in case of severe accident. The use of passive control rods is also an improvement for prevention of severe accident. Moreover, we have in the ESFR SMART core dedicated tubes for corium discharge that should allow discharging quickly the melted materials and should help to prevent large criticality. Calculations show that after several seconds, these discharge tubes begin to open, and the corium arrives by this preferential way on the core catcher, quicker and in limited quantities at the beginning of the accident.

However, the core catcher is designed to be able to retain the whole core meltdown. Its design allows good possibilities of cooling by natural convection of sodium. Some thermal calculations were provided with a multi-layer concept but the global mechanical conception seems difficult. So a one layer core catcher in molybdenum, material compatible with sodium and used on the core catcher of the last SFR, started in 2016: BN 800, is investigated. Explanations are given on the choice of this material proposed for the catcher and used for thermal calculations.

With the proposed design, the corium is spread on the core catcher and the residual power of the corium can be dispelled by natural convection by the sodium circulating around and above the core catcher without boiling of sodium if the melted core is less than about $25 \%$ of whole core. In case of bigger quantities of melted core, boiling of sodium could appear under the core catcher. Further less conservative calculations would be necessary to better know the limit.
\end{abstract}

KEYWORDS: Generation-IV nuclear system, safety, severe accident mitigation 


\section{PURPOSE OF PAPER}

The use of a core catcher able to retain the corium of a melted SFR core is required by safety authorities. The first SFR built, as for example Phenix, did not have core catcher. One of the first SFR to have this type of mitigation device was Superphenix (fig 1).

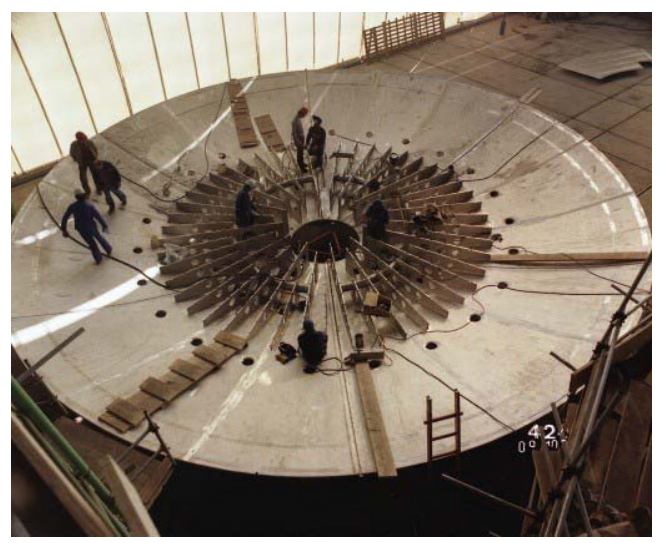

Figure 1. View of the Superphenix core catcher under building.

The last SFR built and operated is BN 800 in Russia (in operation since 2017). A core catcher was also installed in the reactor under the diagrid (see fig 2).

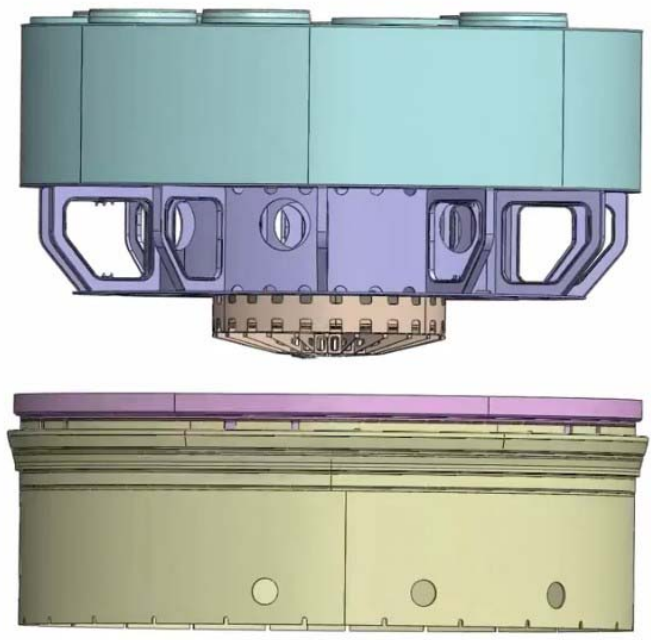

Figure 2. View of the core catcher of BN 800 under the diagrid.

In this core catcher, the upper part is covered with molybdenum, a sodium-compatible material with a very high melting point $\left(2623{ }^{\circ} \mathrm{C}\right)$ and excellent conductivity. After assembly, chimneys also protected by molybdenum are installed to allow a good circulation in natural convection of sodium cooling the lower part of the device, to extract the downward thermal flux.

In the precedent CP-ESFR project, the analyses showed that coolability could be assured for $\sim 10 \%$ of the total corium mass under conservative assumptions regarding heat transfer. Therefore, to improve this internal core catcher mass retention and heat dissipation capacity, several new studies have been conducted in the frame of ESFR SMART project. These studies are shown in this paper with a new design proposition. 


\section{SEVERE ACCIDENT}

The core conception of ESFR SMART with lower void effect has a better behavior in case of severe accident than the previous cores (e.g., the core designed in the frame of the CP-ESFR Project).

Moreover, we have in the ESFR SMART core dedicated tubes for corium discharge that should allow discharging quickly the melted core and should help to prevent criticality. Calculations show that after several seconds, these discharge tubes begin to open, and the corium arrives by this preferential way on the core catcher, quicker and in limited quantities at the beginning of the accident.

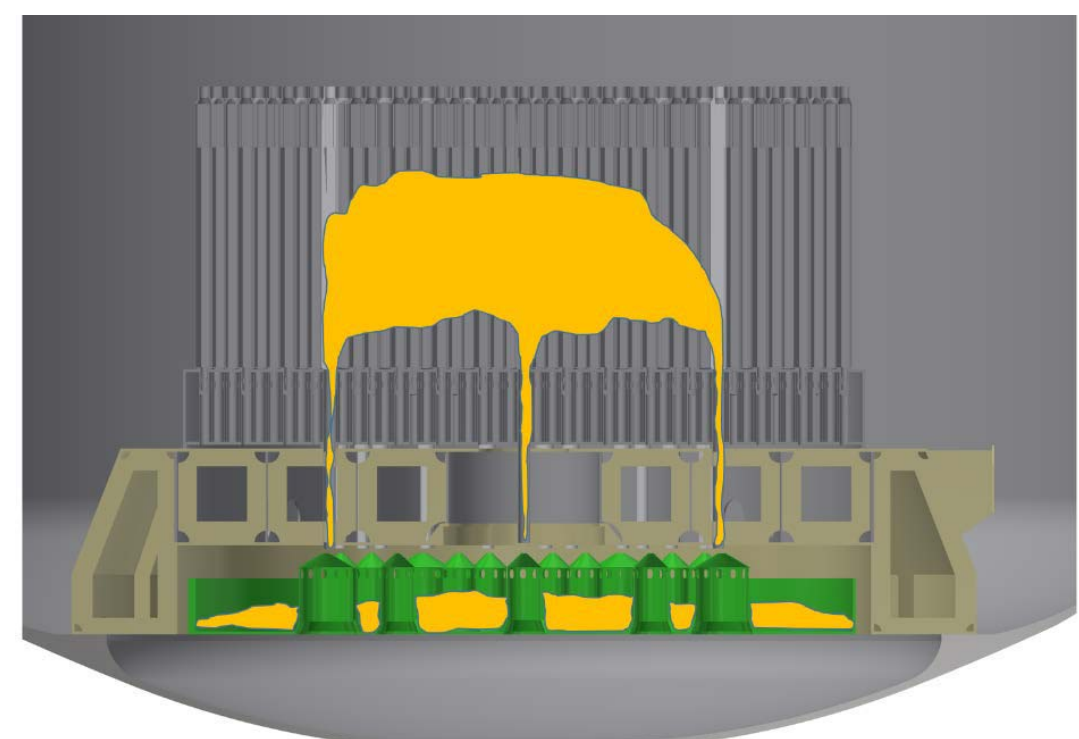

Figure 3. "Artistic view" of the preferential ways for the melted core

However, things are not so simple, because there could be strong interactions between liquid corium around $3000{ }^{\circ} \mathrm{C}$ or liquid steel around $1500{ }^{\circ} \mathrm{C}$, with sodium boiling at $900{ }^{\circ} \mathrm{C}$. This can even lead to situations where the corium could, because of this energetic cooling, solidify before reaching the core catcher. R \& D continues in this area to improve the knowledge of these complex interactions phenomena.

\section{CHOICE OF MATERIAL FOR THE CORE CATCHER}

The core catcher must be equipped with a refractory material to which a number of qualities are required: Compatibility with sodium (for 60 years), good mechanical resistance during a thermal shock, high melting point, good resistance to erosion under a corium jet, easy to machine or to weld, available, affordable. Reactor experience would be a plus, as well as minimal R \& D necessary. The ideal material does not exist, but molybdenum meets a number of these parameters:

- It is totally compatible with sodium (it was used for sodium sample collection in Phenix because it does not pollute sodium).

- With its low coefficient of expansion and high modulus of elasticity, this metal has the best behavior during local thermal shock.

- Its melting point is extremely high $\left(2600{ }^{\circ} \mathrm{C} /\right.$ boiling at more than $\left.4000{ }^{\circ} \mathrm{C}\right)$ which makes it close to ceramics. 
- It has an attitude comparable to ceramics under a jet of molten corium (but worse for a jet of molten metal).

- $\quad$ It is possible to machine or weld it (except some nuances).

- It is available and currently its price is decreasing because of stocks increasingly important (by-product of copper mines), currently its price is around $20 € / \mathrm{kg}$.

- There is experience of its use in sodium, since it is used for BN 800 and therefore currently in sodium, for example in Phenix in the sample collection system.

But two "negative" points should be addressed:

Molybdene has been selected for investigation because and despite its high conductivity. This high conductivity is favorable to increase the thermal exchanges. However, this high conductivity with also increase the downward thermal flux towards the sodium below the core catcher. In case of sodium boiling below the core catcher, its coolability could be degraded. Therefore, the design was proposed to improve the natural circulation of sodium below the core catcher.

The other negative point is the possible creation of a eutectic, at high temperature $\left(1450{ }^{\circ} \mathrm{C}\right)$, under a jet of pure liquid metal. If, at the beginning of the core melting, liquid steel arrived alone and before the corium, the strong interaction with sodium would lead to the arrival of solidified or fractionated steel, with completely different effects than a liquid steel jet in air and any interaction at $1450{ }^{\circ} \mathrm{C}$ would become very difficult or very limited in time.

\section{CORE CATCHER CONCEPT FOR ESFR SMART}

Theoretically, the core catcher could be installed in the primary vessel or directly in the pit. Due to geometrical reasons, in pool-type reactors, sufficient place exists in the primary vessel between the diagrid, the strongback and the vessel for spreading out the corium and then, reducing the risk of criticality and reducing the downward thermal flux. So, this core catcher is installed in this available volume. The option of a core catcher inside the pit itself has not been studied in the ESFR SMART project.

The figure 5 shows in green the position of the core catcher studied in ESFR SMART. The figure 5 also shows the discharge tubes in dark grey arriving from the core above this core catcher.

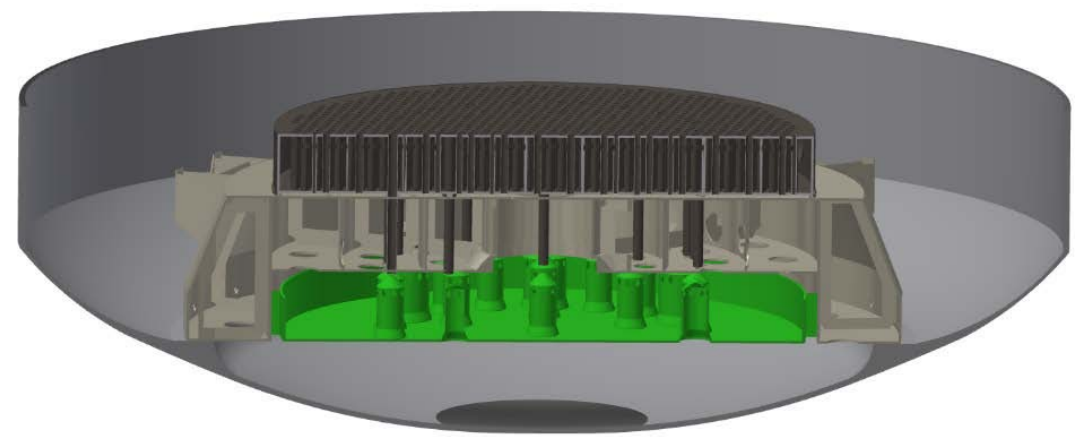

Figure 5. View of the core catcher position inside the primary vessel.

These corium discharge tubes, coming from the core, emerge above the core catcher to channel the molten corium. Cylinders with Chinese hat top endings are installed under these tubes to allow a good dispersion of the corium inside this core catcher (fig. 6) and to avoid or minimize local ablation, during transitory 
periods. The volume available in the core catcher allows receiving the whole core fissile inventory. General design of the strongback structures allow a good circulation of the sodium above and under the core catcher, to improve cooling by sodium natural convection. The general design allows a good circulation of the sodium under the core catcher, to be able to participate actively to the cooling of the component.

Two options remain open:

- The first calculations with only $25 \%$ of molten core show no risk of re-criticality of the corium. The disposition of hafnium-type poisons inside the discharge tubes in the lower part could be used, if necessary, to increase the margin to avoid any re-criticality. This needs further investigations.

- We can replace the cylinders by chimneys (fig. 6) to improve the natural convection of sodium under the core catcher, flowing through the chimneys. (as BN 800 design)

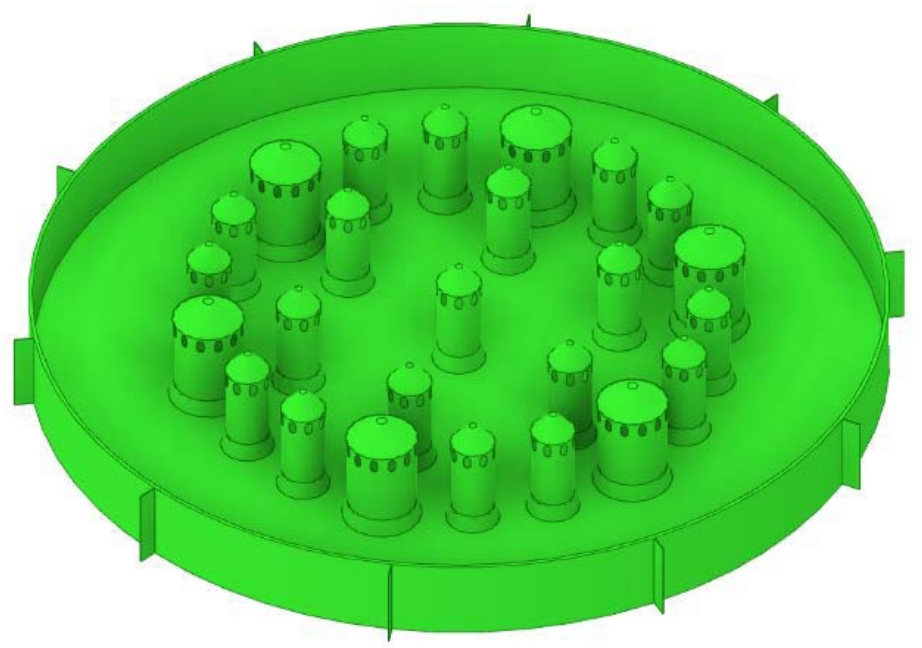

Figure 6. View of the core catcher with chimneys.

\section{RESIDUAL POWER OF THE MELTED CORE}

One of the key parameters of the calculations is the power generated by the corium and its decay with time. This power has been calculated with EVOLCODE (ref 1) when considered the CONF2-HET2 core proposed in the CP-ESFR (ref 2), given that at the date of the beginning of this task, the ESFR-SMART core design was not completed. Table I presents the power generated by the corium at the given time as well as the power density, obtained as the ratio between the power and the total volume of the corium.

Table I. Decay heat generated by the corium. Several time steps after the scram have been considered

\begin{tabular}{ccccccc}
\hline Time (s) & 0.1 & 1 & 10 & 120 & 600 & 1200 \\
$\begin{array}{c}\text { Power (MW) } \\
\begin{array}{c}\text { Power density } \\
\left(\mathbf{M W} / \mathbf{m}^{3}\right)\end{array}\end{array}$ & 427.8 & 394.9 & 273.0 & 176.4 & 133.8 & 115.1 \\
\hline
\end{tabular}


The calculations are performed assuming that the equilibrium thermal state of the corium. The power release is then the residual power of the corium. The heat transfers before the equilibrium state are not calculated. Two simulations are done assuming the equilibrium state is achieved $120 \mathrm{~s}$ or 1200 s after the beginning of the corium subcriticallity.

\section{THERMAL CALCULATIONS}

In order to perform calculations related to the coolability of the core-catcher, it has been necessary for CIEMAT to develop an algorithm (or code) that solves the heat equation in two dimensions.

A verification of this code with a one dimension analysis has been provided with an example of a multilayer core catcher presented in figure 7 (ref 3). The comparison shows in this case a good agreement.

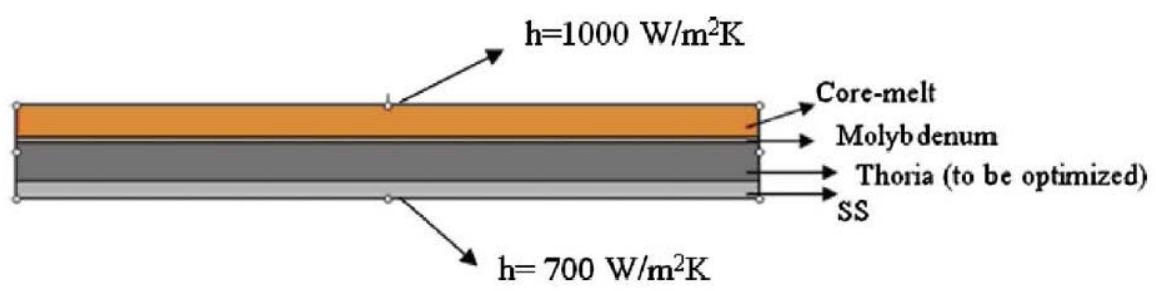

Fig. 7. Geometry of the verification exercise. Figure from ref 3.

Calculations have been provided in two cases, with the same hypothesis of a multi-layer core catcher than in figure 7 , and with a core catcher in one molybdenum layer.

Main hypotheses are following:

- $\quad$ Diameter of the core catcher equals to $8.7 \mathrm{~m}$.

- Corium volume of $31.4 \mathrm{~m}^{3}$.

- Dynamic calculation of the convection coefficients above the corium and below the core catcher according to ref 4.

- Corium considered as a liquid homogeneous mixture of fuel and cladding.

The results are obtained considering a constant conductivity.

As referred in ref 4 , the convection coefficients have addressed a $\pm 25 \%$ uncertainty, so the value employed in the calculation is 0.75 time the calculated convection coefficient. The conductivity of the corium is not that from the fuel, using instead the conductivity reported in ref 6 for the corium, whose value is $7.15 \mathrm{~W} / \mathrm{mK}$ considering the uncertainty of the measurement. Additionally, the heat transfer coefficient through the vertical walls is obtained from ref 5 .

The results show that the total amount of corium mass able to be cooled without sodium boiling by a molybdenum core catcher is reduced with respect to the multilayer core catcher (from $35 \%$ in the multilayer core catcher to $25 \%$ in the molybdenum core catcher). However, the limitation to avoid sodium boiling under the core catcher is not useful. A core catcher in one layer is simpler to fabricate and less expensive than a multi-layer concept. On the other hand, we avoid all difficulties related to the mechanical behaviour of several materials together able to support thermal shocks. The sizing calculations of a component with only one material will be easier. The multi-layer design limits the thermal evacuation possibilities without real benefit.

Therefore, we propose a core catcher in one layer in molybdenum. 


\section{CONCLUSIONS}

As for usual recent SFR projects, the ESFR SMART project has a core catcher inside the primary vessel, under the diagrid and the strongback. Its function, in case of severe accident with core melting, is to retain the corium and to cool it only with the natural convection of sodium around it.

Conservatively, we took the option of a core catcher able to retain the whole melted core. The design of the core catcher takes also advantage of the discharge tubes arriving from the core above this core catcher.

Preliminary thermal calculations were provided with a multi-layer and a one-layer concept. The global mechanical behavior of the multi-layer concept seems difficult, and there is no clear thermal advantage. Therefore, we propose a one-layer core catcher in molybdenum, material compatible with sodium and used on the core catcher of the last SFR, started in 2016, BN 800.

With the proposed design, the residual power of the corium can be dispelled by natural convection by sodium circulating around and above the core catcher. Conservative calculations show that even if $25 \%$ of whole core is on the core catcher, there is no boiling of sodium under the core catcher.

In case of bigger quantities of melted core, boiling of sodium could appear under the core catcher. The chimneys (fig 6) will improve the natural circulation of this sodium located under the core catcher.

At long term the residual power will decrease, and sodium natural convection around this core catcher, will allow a good general mitigation situation.

\section{ACKNOWLEDGMENTS}

The work has been prepared within EU Project ESFR-SMART which has received funding from the EURATOM Research and Training Programme 2014-2018 under the Grant Agreement No. 754501.

\section{REFERENCES}

1. F. Álvarez-Velarde, E.M. González-Romero, I.M. Rodríguez, "Validation of the burn-up code EVOLCODE 2.0 with PWR experimental data and with a Sensitivity/Uncertainty analysis". Ann. Nucl. Energy 73, 175-188 (2014).

2. F. Martín-Fuertes, Transmutation options assessment (2011)

3. A.J. Sudha, K. Velusamy, P. Chellapandi, "A multi layer core catcher concept for future sodium cooled fast reactors". Ann. Nucl. Energy 65, 253-261 (2014).

4. C. Le Rigoleur, D. Tenchine, Département des Réacteurs à Neutrons Rapides, in: International Topical Meeting on Liquid Metal Fast Breeder Reactor Safety and Related Design and Operational Aspects (1982).

5. N. Mukhamedov, M. Skakov, I. Deryavko, I. Kukushkin," Thermal properties of prototype corium of fast reactor", Nucl. Eng. Des. 322, 27-31 (2017).

6. E.M. Sparrow, J.L. Gregg, "Details of exact low Prandtl number boundary-layer solutions for forced and for free convection", NASA Memo 2-27-59 E, (1959). 